\title{
Has the wheat improvement programme succeeded in elating productivity growth across production environments of India?
}

\author{
Devinder Mohan*, Sanjay Kumar Singh, Satish Kumar, Karnam Venkatesh, Gopalareddy \\ Krishnappa and Gyanendra Pratap Singh
}

ICAR-Indian Institute of Wheat and Barley Research, 132001, India

\section{Article history:}

Received: 18 Jan., 2021

Revised: 4 April, 2021

Accepted: 28 April., 2021

\section{Citation:}

Mohan D, SK Singh, S Kumar, K Venkatesh, G Krishnappa and GP Singh. 2021. Has the wheat improvement programme succeeded in elating productivity growth across production environments of India? Journal of Cereal Research 13(1): 107-116. http://doi. org/10.25174/2582-2675/2021/110535

\section{*Corresponding author:}

E-mail: dermohan@gmail.com

(c) Society for Advancement of Wheat and Barley Research

\begin{abstract}
The mean yield of the released and pre-released irrigated bread wheat varieties was examined for the period 1990-2020 to study progress in yield enhancement under ten diverse production environments of India. Productivity growth was examined in two production conditions i.e. timely and late-sown, prevalent in five mega zones of the country. Progression in the timely-sown wheat was prominent in all five zones as the growth rate was highly significant. In the late-sown category, growth was highly significant only in the Indo-Gangetic Plains (IGP) and central India. Yield enhancement in western IGP was continuous and many impactful varieties had been developed the other hand, On quite varietal development was slow in central India. In comparison, varieties released in eastern IGP were large in number but the yield level was not high. Growth in grain number was eminent in most of the environments. Improvement in grain weight was also visible in timely-sown wheat of eastern IGP and peninsular India. Reduction in grain weight had been observed in timely-sown wheat of northern hills. Varietal expression of wheat genotypes had changed a lot in the peninsular region as plant height was reduced in both categories of wheat and maturity duration was reduced in the timely-sown wheat. High deviations and low productivity has made the late-sown wheat vulnerable and non-remunerative in hills and peninsular India.
\end{abstract}

Keywords: Indian bread wheat, production environments, yield determinants

\section{Introduction}

Wheat has a special status in the food system of the Indians. This staple food crop has nearly 30 million hectares ( $\mathrm{m}$ ha) acreage in almost all parts of the country and more than 95\% of wheat cultivation has access to irrigation. Because of wide agro-ecology, the All India Coordinated Research Project on Wheat and Barley (AICRPW\&B) has categorised the whole country into ten major production environments covering two major production conditions i.e. timely-sown (TS) and late-sown (LS) in five mega zones i.e. Northern Hills Zone (NHZ), North Western Plains Zone (NWPZ), North Eastern Plains Zone (NEPZ), Central Zone (CZ) and Peninsular Zone
(PZ). This framework has got appreciation world over for making wheat research a success story in India (Singh et al., 2011). Nevertheless, reviewing the past is crucial to envisage a better future. It is imperative to monitor the progress achieved in productivity enhancement primarily because the success level in developing highyield genotypes and the impact of climate change may not be the same in every production environment. In past, Tandon and Sethi (1986) had reviewed 25 years of coordinated wheat research in India for the period 196186. In continuation, this review has focussed on yield progression in irrigated bread wheat (Triticum aestivum 
L.) during the period 1990-2020. Overall performance of the popular released varieties used as checks and the prereleased varieties under the final year of testing in irrigated advance varietal trials conducted by the AICRPW\&B have been examined for all production environments. This study may will help the researchers in demarcating areas of high yield potential and the environments sensitive to climatic variations. The review also aims to explore the change occurring in the varietal characteristics over a period of time and highlight varieties playing a major role in yield progression. Research priorities keep changing at different times and so is the resource allocation. This study, therefore, shall also be useful in prioritizing the research activities in different parts of the country.

\section{Productivity difference and yield range}

Due to the diverse production environments and genetic makeup of the test entries, productivity levels vary vividly in India. Average yield recorded in multi-location trials had crossed the $5 \mathrm{t} /$ ha mark in many varieties of timelysown wheat (Table 1), but overall productivity had been near to this mark only in NWPZ as the mean yield in majority of the genotypes was $5 \mathrm{t} / \mathrm{ha}$. Prospects of raising the tonnage beyond $6 \mathrm{t} /$ ha appear quite high in NWPZ as it is the only zone where mean yield in certain varieties had exceeded this bench mark in recent years. Productivity in the adjoining NEPZ was lowest (4t/ha) amongst all the zones as the majority of the material recorded yield between 3.5 to $4.5 \mathrm{t} / \mathrm{ha}$. $\mathrm{CZ}$ is the $2^{\text {nd }}$ high-yield territory in the country. Although majority of the genotypes yielded around $5 \mathrm{t} / \mathrm{ha}$ under CZ-TS condition, entries of mean yield around $4 \mathrm{t} /$ ha was also in plenty. Overall productivity in PZ and NHZ were 15 and 17 per cent less in comparison to NWPZ and genotypes of $3 \mathrm{t} / \mathrm{ha}$ yield could also be traced in timely-sown wheat of these two zones.

Table 1. Overall productivity ( $\mathrm{q} / \mathrm{ha})$, genotypic diversity and frequency distribution in test entries

\begin{tabular}{|c|c|c|c|c|c|c|c|c|c|c|}
\hline \multirow[t]{2}{*}{ Zone } & \multirow{2}{*}{$\begin{array}{l}\text { Years of } \\
\text { testing }\end{array}$} & \multirow{2}{*}{$\begin{array}{l}\text { Number } \\
\text { of entries }\end{array}$} & \multicolumn{3}{|c|}{ Yield and extent of variation } & \multicolumn{5}{|c|}{ Frequency distribution in test entries (\%) } \\
\hline & & & Mean & Range & CV $(\%)$ & $56-65$ & $46-55$ & $36-45$ & $26-35$ & $\leq 25$ \\
\hline \multicolumn{11}{|c|}{ Timely-sown wheat } \\
\hline NHZ & 29 & 146 & 41.3 & $25-57$ & 14.9 & 00.7 & 26.7 & 51.4 & 20.5 & 0.7 \\
\hline NWPZ & 31 & 178 & 49.7 & $39-64$ & 10.0 & 12.9 & 73.0 & 14.0 & 00.0 & 0.0 \\
\hline NEPZ & 30 & 232 & 40.3 & $31-51$ & 10.0 & 00.0 & 12.9 & 72.8 & 14.2 & 0.0 \\
\hline $\mathrm{CZ}$ & 29 & 100 & 46.2 & $34-59$ & 09.6 & 04.0 & 59.0 & 36.0 & 01.0 & 0.0 \\
\hline $\mathrm{PZ}$ & 31 & 119 & 42.4 & $30-51$ & 11.8 & 0.0 & 30.8 & 58.1 & 11.1 & 0.0 \\
\hline \multicolumn{11}{|c|}{ Late-sown wheat } \\
\hline NHZ & 26 & 84 & 27.5 & $18-46$ & 20.0 & 00.0 & 01.2 & 08.3 & 48.8 & 41.7 \\
\hline NWPZ & 30 & 177 & 40.3 & $31-51$ & 10.5 & 00.0 & 11.1 & 78.4 & 10.5 & 00.0 \\
\hline NEPZ & 25 & 152 & 34.0 & $23-42$ & 11.5 & 00.0 & 00.0 & 39.5 & 57.2 & 03.3 \\
\hline $\mathrm{CZ}$ & 29 & 129 & 41.5 & $27-55$ & 10.6 & 00.0 & 14.7 & 80.6 & 04.7 & 00.0 \\
\hline PZ & 28 & 132 & 36.9 & $25-46$ & 11.1 & 00.0 & 00.8 & 65.6 & 32.8 & 00.8 \\
\hline
\end{tabular}

Under late-sown condition also, the productivity of wheat was highest in CZ and NWPZ and the majority of the genotypes had registered yield level of $4 \mathrm{t} / \mathrm{ha}$. A good number of the genotypes in these two zones expressed productivity range of 4.5 to $5.5 \mathrm{t} /$ ha even in the late-sown wheat. In comparison, the average yield level in NEPZ was only $3.4 \mathrm{t} / \mathrm{ha}$ and the majority of the test materials yielded in between 3 to $4 \mathrm{t} / \mathrm{ha}$. Average productivity rarely exceeded the $4 \mathrm{t} / \mathrm{ha}$ threshold under the NEPZ-

LS condition. Although the maturity period of latesown wheat was very small in PZ (98 days), the average productivity in the zone was higher than NEPZ, a zone where the crop demanded an extra 10 days to mature. The yielding ability of the late-sown wheat had been very low in NHZ as one-fourth material could not yield more than $2.5 \mathrm{t} / \mathrm{ha}$. Amongst all zones, coefficient of variation $(\mathrm{CV})$ was also highest in $\mathrm{NHZ}$ in both categories of wheat i.e. timely-sown and late-sown. 


\section{Success in varietal development}

Amongst the new test entries, genotypes that reach the final year of testing (generally $3^{\text {rd }}$ year of testing in the national coordinated trials) are examined for release in that particular environment. If NWPZ, the most productive wheat land in the country is taken as standard, its share in total final year test entries examined in the country was less than NEPZ in both categories of wheat (Table 2). The success rate in variety release (percentage of genotypes selected for notification out of the final year entries of that production environment) was however far more impressive in NWPZ. The success rate was lowest in NHZ-TS and NEPZ-LS environments. Even though CZ always expressed high yield, fewer test entries could reach the final year. In comparison, $\mathrm{PZ}$ not only exhibited better success rate than $\mathrm{CZ}$ but it also had more genotypes in race to qualify as variety. Low success rate in NHZ had been reported in some earlier reports also (Shoran et al., 1998).

Table 2. Success in variety release

\begin{tabular}{|c|c|c|c|c|c|c|c|c|c|c|}
\hline \multirow[t]{2}{*}{ Parameter } & \multicolumn{5}{|c|}{ Timely-sown wheat } & \multicolumn{5}{|c|}{ Late-sown wheat } \\
\hline & NHZ & NWPZ & NEPZ & $\mathrm{CZ}$ & PZ & NHZ & NWPZ & NEPZ & $\mathrm{CZ}$ & $\mathrm{PZ}$ \\
\hline Final year test entries & 46 & 45 & 95 & 27 & 35 & 19 & 47 & 65 & 36 & 40 \\
\hline Varieties notified & 7 & 15 & 19 & 6 & 10 & 4 & 16 & 10 & 9 & 10 \\
\hline Success percentage & 15 & 33 & 20 & 22 & 29 & 21 & 34 & 15 & 25 & 25 \\
\hline
\end{tabular}

This analysis indicated that the flow of the promising newly bred genotypes had started drying up in certain production environments, especially under late-sown conditions. For similar reason, trials could not be conducted for 2-3 years under CZ-LS, PZ-LS, NHZ-TS and CZ-TS condition. The urgency to boost productivity in NEPZ and exploit productivity potential in CZ had got a big miss. Because of the large wheat acreage in NEPZ (9.1 $\mathrm{m}$ ha) and CZ (7.2 $\mathrm{m}$ ha), big efforts are required to strengthen productivity growth in these two regions.

\section{Extent of yield gain}

When mean yield of the initial three-years (1900-92) was compared with the last three years of testing (2018-20), significant improvement was apparent in most of the production environments (Table 3). Yield gain was highest in CZ and NWPZ, in both production conditions. Initially, productivity level was almost same in $\mathrm{CZ}$ and NWPZ in both production conditions but in the closing years, yield in NWPZ shot up at a higher pace in comparison to CZ in the timely-sown wheat whereas $\mathrm{CZ}$ had this edge in the late-sown wheat. In NEPZ-LS, yield gain up to 2018-20 could not be estimated as trials were not conducted during the last phase of this study. However, if the comparison is made against 2012-14, yield gain was substantial in that environment too. Productivity gain in $\mathrm{NHZ}$ and $\mathrm{PZ}$ was impressive in timely-sown wheat.

Table 3. Yield gain and rate of growth in different production environments of India

\begin{tabular}{lcccc}
\hline Zone & \multicolumn{3}{c}{ Mean yield $(\mathbf{q} / \mathbf{h a})$} & $\begin{array}{c}\text { Coefficient of } \\
\text { determination }\left(\mathbf{R}^{2}\right)\end{array}$ \\
\cline { 2 - 3 } Timely-sown wheat & Initial 3 years & Closing 3 years & \% gain & $0.231^{* * *}$ \\
NHZ & 39.50 & 45.21 & 14.5 & $0.572^{* * *}$ \\
NWPZ & 46.03 & 58.75 & 27.6 & $0.453^{* * *}$ \\
NEPZ & 36.84 & 47.21 & 28.1 & $0.643^{* * *}$ \\
CZ & 45.35 & 56.48 & 24.5 & $0.264^{* *}$ \\
PZ & 39.69 & 46.60 & 17.4 & 0.121 \\
Late-sown wheat & & & 09.9 & $0.514^{* * *}$ \\
NHZ & 25.67 & 28.22 & 20.1 & $0.376^{* * *}$ \\
NWPZ & 38.80 & 46.59 & 41.1 & $0.450^{* * *}$ \\
NEPZ & 27.45 & 38.73 & 35.7 & $0.180^{*}$ \\
CZ & 37.53 & 50.94 & 12.5 & \\
PZ & 34.99 & 39.36 & & \\
\hline
\end{tabular}




\section{Progression in productivity enhancement}

Varietal development is a continuous process. The genotypes included as pre-release or released varieties also keep changing in the yield evaluation trials as new test materials keep coming and the old varieties used as checks are replaced by the newly released varieties. To gauge continuity in growth at the time scale (year), the mean yield of all the genotypes tested in a particular year was derived and it was computed for 31 years of this study period to calculate the coefficient of determination $\left(\mathrm{R}^{2}\right)$ through regression analysis. Although some productivity improvement was visible in three decades, the growth rate across the country was highly significant only in timely-sown wheat (Table 3). In late-sown wheat, yield progression was highly significant only in three zones i.e. NWPZ, NEPZ and CZ. The growth rate was significant in NEPZ-LS but only up to 2014. Per cent yield gain achieved during three decades (Table 3) did not commensurate with the coefficient of determination which underlined that the impact of climatic variations was highly divergent in different production environments which means that the changes occurring in the environment had registered diverse impact on wheat productivity. A significant positive impact of global environmental change (GEC) in CZ-TS and non-significant in NWPZ-TS had been reported in India by Mohan (2014) and Mohan et al., 2020. The low $\mathrm{R}^{2}$ value in $\mathrm{NHZ}$ underlined that the climatic variations must be very high in the hills. When year-wise variation in mean productivity was measured by the coefficient of variation $(\mathrm{CV})$, it was observed that yield deviation in the tested material was highest in the hills during this study period (Table 1). Apart from weather vagaries, high variations in NHZ could also have occurred due to the varying number of test sites during this long study period. It indicates that besides low productivity, poor growth rate and weather vagaries also supported the worthlessness of late-sown wheat in NHZ.

\section{Shift in varietal characteristics}

Yield increase before the start of the $21^{\text {st }}$ century has largely been taken as a consequence of changes occurring in grain bearing, grain weight and the phenological expressions (Slafer et al., 1996; Rajaram and Ginkel, 1996). Later on climate change was regarded as a big yield influencing factor (Mohan et al., 2011; Rajaram, 2012; Sharma et al., 2013). According to Rajaram and Braun
(2008), breeding for high yield potential and biotic stress tolerance is the norm in a favourable environment but under abiotic stress, yield potential is often ignored as focus shifts to stress tolerance. Wheat yield is better related to grain number per $\mathrm{m}^{2}$ than to individual grain weight (Slafer and Andrade, 1989; Magrin et al., 1993; Slafer et al., 1994). The period around and before anthesis, when the grains $/ \mathrm{m}^{2}$ is established, has been largely recognised as being critical. Traditionally, improvement in grain number had been emphasized whereas grain weight had undergone only smaller change (Slafer et al., 1996). Rajaram and Ginkel (1996) from CIMMYT opined that after having achieved a large number of grains $/ \mathrm{m}^{2}$ in Veery and Attila lines, the grain size got automatically adjusted to a somewhat smaller grain size and this regulatory mechanism need to broken by giving more emphasis to grain weight. In countries like China, grain weight had been an important selection criterion (Zhonghu and Bonjean, 2013). Grain weight in modern cultivars might be co-limited by both sources and sink strengths (Slafer et al., 1996). Thus, breaking the yield barrier of yield potential in wheat will require a simultaneous increase in grain number and available assimilates to avoid developing competitive restrictions to grain growth. Some research findings underline that smaller dwarf wheat genotypes suffer relatively less growth reduction by drought stress than the large (and more competitive) tall genotypes (Slafer et al., 1996). Since wheat breeding in India is handled in diverse production environments, exploitation of varietal traits for yield enrichment may vary. In the era of climate change, it is obvious to locate certain change in the varietal expression which must have engineered yield up-gradation during thrree decades of the study period. To observe a shift in varietal expressions, the annual mean of the yield components like plant height, days to heading, grain ripening duration, grain weight and the number of grains $/ \mathrm{m}^{2}$ were also regressed against the time scale.

It was observed that productivity elevation in the two most productive wheat zones of the country i.e. NWPZ and $\mathrm{CZ}$ had been realized through an increased number of grains per unit area (Table 4). Since the growth rate in grain weight was non-significant, improvement must have occurred in the spike number i.e. tiller number. There was also has been a steady increase in the maturity period of timely-sown varieties in NWPZ. In NEPZ, grain number had increased by small a margin in the timely- 
sown wheat but the growth rate in grain weight was highly significant. It means that there had been very little success in elating tillering potential of timely-sown wheat varieties. The trend was quite different in the late-sown wheat of the region as progression was highly significant in grain number (up-to 2014) but gain in grain weight was missing. The shift in varietal expressions had been quite different in PZ where yield growth had been derived through grain weight under the timely-sown condition and grain number under the late-sown condition. The average TGW in the most recent timely-sown varieties of PZ (MACS 6222, MACS 6478 and DBW168) was $42.8 \mathrm{~g}$ during the five year period (2016-2020). In comparison, TGW in the varieties of the initial five-year block (DWR
162, HD 2189, HD 2830 and MACS 2496) was $40.6 \mathrm{~g}$. Plant height had been gradually reduced in PZ in both growing conditions of wheat i.e. timely-sown as well as late sown. There had been a gradual decline in maturity duration and vegetative period of timely-sown varieties in PZ. In NHZ, new high yielding genotypes expressed better grain number but there was decline in the grain weight. Grain number and grain weight could not be improved in late-sown varieties of NHZ. There was an improvement in plant height and grain filling duration under NHZ-LS condition but it had no bearing on the grain weight or grain yield, probably due to lower biomass accumulation in the shortened vegetative phase.

Table 4. Progression in major yield determinants

\begin{tabular}{llcccccc}
\hline Zone & $\begin{array}{l}\text { Production } \\
\text { Environment }\end{array}$ & $\begin{array}{c}\text { Grain } \\
\text { weight }\end{array}$ & $\begin{array}{c}\text { Grain } \\
\text { number }\end{array}$ & $\begin{array}{c}\text { Plant } \\
\text { height }\end{array}$ & $\begin{array}{c}\text { Vegetative } \\
\text { period }\end{array}$ & $\begin{array}{c}\text { Reproductive } \\
\text { period }\end{array}$ & $\begin{array}{c}\text { Maturity } \\
\text { period }\end{array}$ \\
\hline NHZ & Timely-sown & $-0.18^{*}$ & $0.29^{* *}$ & 0.06 & 0.00 & 0.03 & 0.03 \\
& Late-sown & 0.02 & 0.05 & $0.15^{*}$ & -0.10 & $0.27^{* *}$ & 0.01 \\
NWPZ & Timely-sown & 0.06 & $0.40^{* * *}$ & 0.03 & 0.07 & 0.05 & $0.14^{*}$ \\
& Late-sown & -0.05 & $0.55^{* * *}$ & -0.05 & -0.06 & 0.04 & 0.11 \\
NEPZ & Timely-sown & $0.33^{* * *}$ & $0.15^{*}$ & 0.06 & 0.05 & 0.12 & 0.10 \\
& Late-sown & 0.01 & $0.32^{* * *}$ & 0.03 & 0.11 & 0.02 & 0.00 \\
CZ & Timely-sown & 0.09 & $0.38^{* * *}$ & 0.00 & -0.01 & 0.00 & 0.01 \\
& Late-sown & 0.00 & $0.43^{* * *}$ & -0.03 & 0.00 & 0.00 & 0.06 \\
PZ & Timely-sown & $0.24^{* *}$ & 0.08 & $-0.15^{*}$ & $-0.13^{*}$ & 0.00 & $-0.15^{*}$ \\
& Late-sown & 0.01 & $0.20^{*}$ & $-0.29^{* *}$ & 0.00 & 0.02 & 0.02 \\
\hline
\end{tabular}

*, ** and ${ }^{* * *}$ denote significance of $\mathrm{R}^{2}$ at $P 0.05,0.01$ and $\leq 0.001$, respectively

\section{Productivity enhancement at different time intervals}

There are certain reports where growth in wheat productivity has been summarised for different time periods taking into account the total production and wheat acreage in the country (Rajaram, 2012; Sharma et al., 2013). These reports had underlined reduction in yield growth rate during the period 1995-2005 in several countries including India when the comparison was made with the preceding 30 years. An attempt had been made earlier by Mohan et al. (2017) to highlight yield progression in different production environments of India was for the period 2000-2016 and highly significant improvement in wheat productivity was reported in timely-sown wheat of NWPZ and CZ. The outcome of any varietal development programme keeps changing and 31 years is a big period. Therefore, this study period was further divided in 3 decades and progression in wheat productivity was compared decade-wise (Fig. 1).

Success in yield enhancement had been tremendous in the last decade of this study period i.e. 2010-2020. If the yield of wheat varieties under testing is statistically compared decadewise by "t-test", productivity in the final decade (2010-2020) was highly significant in comparison to the preceding decade i.e. 2000-2009 in all production environments except NHZLS and PZ-LS. Recent efforts made for yield enhancement hadresulted in the development of some impactful varieties in many production environments. Timely-sown yield in the recent decade had crossed the $5 \mathrm{t}$ /ha mark in NWPZ and CZ. Varieties like WH 1105, HD 3086 and HD 2967 in NWPZ and HI 1544 in CZ had contributed in a big way to attain 


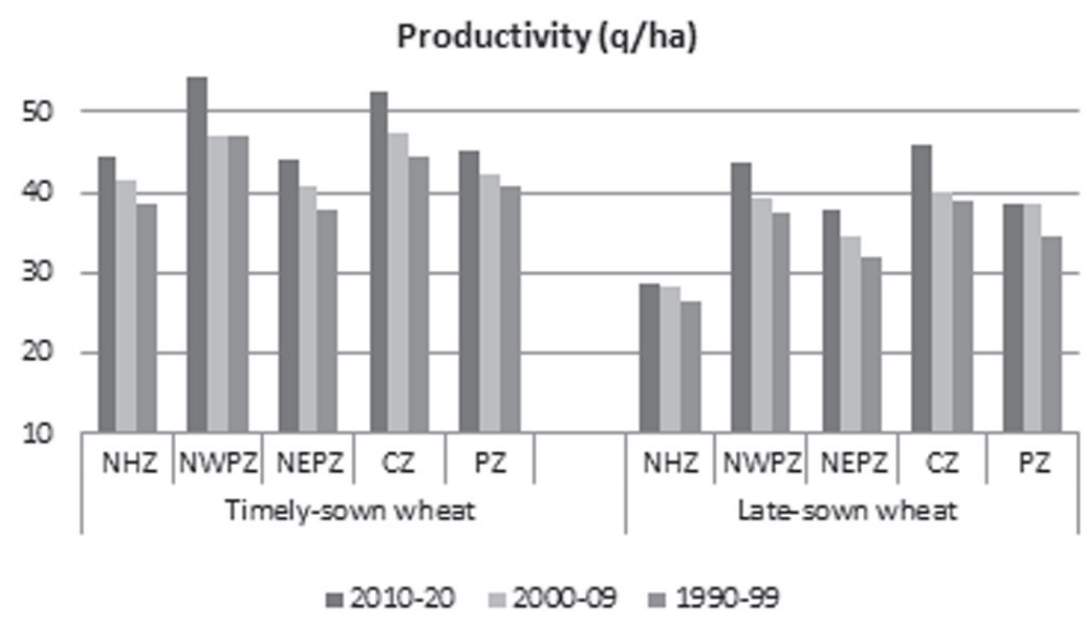

Fig. 1 Productivity enhancement in different decades

such standards. In the other three zones, productivity in the last decade hovered around $4.5 \mathrm{t} / \mathrm{ha}$. Varieties like HS 562 in NHZ, DBW 187 in NEPZ and MACS 6478 were some outstanding varieties of the last decade. Comparison of the first and second decade revealed no significant yield gain in the NWPZ-TS, PZ-TS, CZ-LS and NHZ-LS environments. It reflects that varieties developed in these production environments during the period 2000-2009 had the same yield levels as recorded in the previous decade. In NWPZ$\mathrm{TS}$, the average yield was already quite high initially (4.7 t/ ha) as the improved high yield cultivars like PBW 343, UP 2338, WH 542 and HD 2867 were under cultivation in the $1^{\text {st }}$ decade (1999-2000), too. Genotypes developed thereafter in the $2^{\text {nd }}$ decade like PBW 502, PBW 550 and DBW 17 could make no big dent in the yield. GW 322, a widely adopted genotype of $\mathrm{CZ}$, was the most powerful timely-sown variety of the period 2000-2009 but average productivity of the decade was almost similar to the previous decade because LOK 1, a low yield check, was part of the this study block. Although high yielding genotypes of PZ genotypes like GW 322, NIAW 917 and RAJ 4037 were released in the $2^{\text {nd }}$ decade, yield jump over the previous decade was nonsignificant. In the late-sown category, the most impactful varieties of NWPZ (PBW 771, HD 3059, WH 1124 and DBW 173), NEPZ (HI 1563) and CZ (HD 2932) arrived in the last decade of this study period. Decade-wise yield differences could not precipitate in the NHZ-LS environment as mean yield remained in between 2.6 to $2.9 \mathrm{t} /$ ha in different decades.

\section{Chronology in yield gain}

Varieties suitable for different production environments had been notified at different times. Any time frame therefore cannot be fixed to compare the yield gain from new interventions. Hence, to study the impact of varieties developed during this time scale, the study period was considered only to assess the productivity level at different time intervals. Since many varieties had been notified during this period and some of them had similar yield, different groups were made involving the prominent cultivars and a comparison was made at different time intervals (Table 5).

\subsection{North Western Plains Zone}

NWPZ covering Punjab, Haryana, Delhi, Rajasthan (except Kota and Udaipur divisions) and Westertn UP (except Jhansi division), parts of J\&K (Jammu and Kathua distt.) and parts of HP (Una distt. and Paonta valley) and Uttaranchal (Tarai region) is the most productive wheat zone in the country. A highly significant growth rate under both production conditions clearly demonstrates that varietal development efforts in this zone have given good results continuously. During the 31 years, 15-16 varieties were notified in each production condition (Table 2). HD 2329 was the most popular timely-sown variety of this region in the initial years of this study period. Subsequently, UP 2338. WH 542 and PBW 343 provided the impetus to wheat productivity under timely-sown condition but varieties like PBW 502 and HD 2687 were just an improved version of PBW 343. PBW 550 and DBW 17 did provide some boost to wheat productivity but the upward trend started happening with the remergence of HD 2967, WH 1105, HD 3086 and DBW 88. Latest additions in this category i.e. DBW 187, DBW 222 and HD 3226 have the potential to raise the productivity 
level beyond $6.0 \mathrm{t} / \mathrm{ha}$. Under the late-sown condition, an initial bunch of varieties like PBW 373, RAJ 3675 and UP 2425 were slightly better than the old cultivars. The small improvement over this lot was achieved through varieties like WH 1021, PBW 590 and DBW 16. Quantum jump in the NWPZ-LS environment was realized with the arrival of WH 1124, HD 3059, DBW 71 and DBW 90. The notification of few other high yielding genotypes i.e. DBW 173 and PBW 771 further improved the prospects of grain harvest in this region.

\subsection{North Eastern Plains Zone}

NEPZ is an important zone for wheat production covers Eastern UP, Bihar, Jharkhand, West Bengal and plains of NE states. The maximum area and wheat production in India comes from Uttar Pradesh, a state falling in this zone. The largest number of timely-sown varieties (19) had been notified for this zone but for the late-sown situation, only 10 genotypes could qualify. HUW 206 and K 88 were the two popular timely-sown wheat varieties in the initial years. Varieties released till 2008 i.e. NW 1012, HUW 468 and K 9017 could just make a small impression in wheat yield. In the $21^{\text {st }}$ century, a lot of varieties had been added to the list like HD 2733, PBW 343, PBW 443, K 307, CBW 38, DBW 39, K 1006 and NI 5054 but yield gain was not impressive. Wheat productivity came near to the $5 \mathrm{t} / \mathrm{ha}$ threshold only after the relase of DBW 187 in the year 2017. The situation under the late-sown condition started improving with the arrival of NW 1014, DBW 14 and NW 2036. Productivity improved further when HD 2985 and HI 1563 were released. The late-sown programme thereafter has remained non-productive in NEPZ. Some late-sown varieties identified in this zone in 2014 i.e. DBW 107 and HD 3118, did register yield advantage over HI 1563 but the gain could not be confirmed as the late-sown trial was not conducted thereafter.

Table 5. Average productivity of prominent varieties at different time interval

\begin{tabular}{|c|c|c|c|c|c|c|}
\hline \multirow[t]{2}{*}{ Zone } & \multicolumn{3}{|c|}{ Timely-sown wheat } & \multicolumn{3}{|c|}{ Late-sown wheat } \\
\hline & Period & Varieties & $\begin{array}{l}\text { Yield } \\
\text { (q/ha) }\end{array}$ & Period & Varieties & $\begin{array}{l}\text { Yield } \\
\text { (q/ha) }\end{array}$ \\
\hline \multirow[t]{3}{*}{ NHZ } & $1990-1993$ & HS 240 & 39.7 & $1995-2007$ & HS 295 & 28.3 \\
\hline & $1994-2014$ & $\begin{array}{l}\text { VL } 738, \text { VL 907, HS } 507 \& \\
\text { HPW } 349\end{array}$ & 44.2 & 2008-2019 & HS 490 \& VL 892 & 29.3 \\
\hline & $2015-2020$ & HS 562 & 49.1 & & & \\
\hline \multirow[t]{5}{*}{ NWPZ } & $1990-1993$ & WL 711 \& HD 2329 & 45.1 & 1990-1995 & $\begin{array}{l}\text { PBW 226, RAJ } 3077 \& \\
\text { HD } 2285\end{array}$ & 37.7 \\
\hline & $1994-2005$ & $\begin{array}{l}\text { UP } 2338, \text { PBW } 343 \text { \& } \\
\text { WH } 542\end{array}$ & 48.4 & $1996-2004$ & $\begin{array}{l}\text { RAJ } 3765, \text { PBW } 373 \& \\
\text { UP } 2425\end{array}$ & 38.9 \\
\hline & 2006-2012 & PBW 550 \& DBW 17 & 49.4 & 2005-2012 & $\begin{array}{l}\text { DBW 16, PBW } 590 \text { \& } \\
\text { WH } 1021\end{array}$ & 40.1 \\
\hline & $2013-2017$ & $\begin{array}{l}\text { HD 2967, WH } 1105 \& \\
\text { HD } 3086\end{array}$ & 53.1 & 2013-2017 & $\begin{array}{l}\text { HD 3059, DBW } 90 \& \\
\text { WH } 1124\end{array}$ & 45.0 \\
\hline & $2018-2020$ & DBW 222 & 61.3 & $2018-2020$ & DBW 173 \& PBW 771 & 49.0 \\
\hline \multirow[t]{5}{*}{ NEPZ } & 1990-1996 & HUW 206 \& K 8804 & 38.8 & 1990-1996 & $\begin{array}{l}\text { HP } 1744 \text {, HUW } 234 \& \\
\text { HP } 1209\end{array}$ & 31.7 \\
\hline & $1997-2000$ & NW 1012, K 9107 \& HUW 468 & 39.8 & $1997-2008$ & $\begin{array}{l}\text { NW 1014, DBW } 14 \text { \& } \\
\text { NW } 2036\end{array}$ & 34.4 \\
\hline & 2001-2008 & HD 2733, PBW 343 \& K 307 & 41.4 & 2009-2014 & HD 2985 \& HI 1563 & 38.2 \\
\hline & 2009-2017 & K 1006 \& DBW 39 & 43.2 & & & \\
\hline & $2017-2020$ & DBW 187 & 49.3 & & & \\
\hline \multirow[t]{2}{*}{$\mathrm{CZ}$} & 1990-1993 & WH 147 \& HI 1077 & 44.7 & $1990-2000$ & GW 173, LOK 1 \& SWATI & 39.0 \\
\hline & $1994-2000$ & GW 190, GW 273 \& DL 803-3 & 45.0 & $2001-2007$ & DL 788-2 \& MP 4010 & 39.9 \\
\hline
\end{tabular}




\begin{tabular}{|c|c|c|c|c|c|c|}
\hline & $2001-2020$ & GW 322, GW 366 \& HI 1544 & 51.5 & $2008-2020$ & $\begin{array}{l}\text { HD } 2932, \text { HD } 2864 \& \\
\text { MP } 3336\end{array}$ & 45.6 \\
\hline \multirow[t]{3}{*}{$\mathrm{PZ}$} & $1990-2000$ & MACS 2496 \& HD 2189 & 39.6 & $1990-2000$ & DWR 195 \& HD 2501 & 33.3 \\
\hline & 2001-2012 & $\begin{array}{l}\text { GW 322, NIAW } 917 \text { \& } \\
\text { RAJ } 4037\end{array}$ & 43.9 & $2001-2005$ & NIAW 34 \& HI 977 & 36.4 \\
\hline & 2013-2019 & MACS 6222 \& MACS 6478 & 45.8 & 2006-2019 & RAJ 4083 \& HD 2932 & 39.5 \\
\hline
\end{tabular}

\subsection{Central Zone}

In this $2^{\text {nd }}$ most productive zone (Madhya Pradesh, Chhattisgarh, Gujarat, Kota and Udaipur divisions of Rajasthan and Jhansi division of Uttar Pradesh) of the country, in the past three decades, just 6 varieties for timely-sown and 9 for the late-sown condition could be identified by the coordinated programme. In comparision to the old cultivars namely HI 1077 and WH 147; an initial group of high-yield genotypes i.e. GW 190, DL 803-3 and GW 273 could not push the yield further. Only two varieties i.e. GW 322 and HI 1544 could stand out under timely-sown conditions during these three decades. GW 322 arrived in 2001, whereas HI 1544 was identified in 2007. In the common harvest season i.e. 2007-2020, both genotypes expressed the same yield level (GW: $52.7 \mathrm{q} / \mathrm{ha}$; HI 1544: $52.4 \mathrm{q} / \mathrm{ha}$ ). The situation was almost similar in late-sown category where only three varieties namely $\mathrm{HD}$ 2932, HD 2864 and MP 3336 could provide productivity boost in the region. Two new varieties (CG 1029 and HI 1634) added to this list in 2020, are expected to provide a further push in the productivity of late-sown wheat.

\subsection{Peninsular Zone}

PZ covers Maharashtra, Karnataka, Andhra Pradesh, Goa, plains of Tamil Nadu Hilly areas of Tamil Nadu and Kerala comprising the Nilgiri and Palni hills of southern plateau. Unlike CZ, progress in productivity enhancement was continous and new alternates were coming at regular interval. Though PZ has a small wheat acreage in comparison to all other zones located in the Indian plains, 10 varieties were notified for each production condition during this study period (Table 2). Productivity in the old cultivars of the timely-sown condition i.e. HD 2189 and MACS 2496 was below $4 \mathrm{t} / \mathrm{ha}$. Yield increased by a good margin when NIAW 917, RAJ 4037 and GW 322 were released. MACS 6222 and MACS 6478 are the other two impactful wheat varieties of the region. Under late-sown condition also, the productivity of early phase varieties (DWR 195 and HD 2501) was improved when HI 977 and NIAW 34 were released. The latest bunch of varieties i.e. RAJ 4083 and HD 2932 have taken the late-sown productivity wheat level near to $4 \mathrm{t} / \mathrm{ha}$.

\subsection{Northern Hills Zone}

This hill region covering Western Himalayan regions of J\&K (except Jammu and Kathua distt.); Himachal Pradesh (except Una and Paonta Valley); Uttaranchal (except Tarai area); Sikkim and hills of West Bengal and North Eastern States has a small area under wheat cultivation $(0.9 \mathrm{~m} \mathrm{ha})$ and the breeding centres are also few, therefore only a handful of varieties could be added to the wheat bouquet. In comparison to the old check HS 240; new varieties of timely-sown condition namely VL 738, VL 907, HS 507 and HPW 349 have managed to push the wheat productivity level beyond $4 \mathrm{t} / \mathrm{ha}$. Wheat productivity has crossed the $5 \mathrm{t} /$ ha benchmark with the release of HS 562 in recent time. The late-sown trial under irrigated condition was started in 1994 only and the prominent variety of that period was HS 295. Only 4 varieties had been released thereafter and average productivity has yet to cross $3 \mathrm{t} / \mathrm{ha}$.

\section{Way forward}

Productivity up-gradation is the main motto in any varietal development programme but the efforts made through varietal development cannot be equally productive in every production environment, especially when yield fluctuations become so common in the era of climate change. It is therefore, necessary to identify the environments which are not only productive but its sustainability is also there. Significant changes occurring in the varietal expression over the time scale is another area of interest for the breeders to identify the factors contributing to yield advancement as they can capitalize more on such yield determinants. This review may help to mark the areas where the growth rate has missed the targets so that corrective measures could be taken. A good success was noted in wheat bowl of the country i.e. NWPZ which represents $12.1 \mathrm{~m}$ ha area; while yield progression has been elusive in the adjoining wheat belt of 
$9.12 \mathrm{~m}$ ha i.e. NEPZ. New varieties kept coming regularly in NWPZ which provided a boost to wheat productivity and the yield potential. In NEPZ however, the varietal development programme was not that vibrant, although a lot of material had been tested in this region. According to Ortiz et al. (2008), influence of global warming in the form of terminal heat stress can be quite threatening in this production environment which could be the one of the reason of low productivity. Around 50\% of the varieties released in NEPZ during this study period (10 out of 20 in timely-sown and 5 out of 10 in the late-sown category) were actually contributed by the breeding centres located in other zones like Karnal, Indore, Wellington, New Delhi, Ludhiana and Durgapura. In CZ, little material was available for churning and few impactful varieties had been developed in the later half under both production conditions. Good materials were available for testing at regular interval in PZ but growth rate was not impressive in the late-sown wheat.

Traditionally, CZ has been recognised in the country for bold grain size. Grains of present timely sown varieties of the region (GW 322 and HI 1544) are also quite attractive but now PZ has emerged as a new territory of bold grains with varieties like MACS 6222, MACS 6478 and DBW 168. TGW in PZ varieties (43.0 g) has surpassed $\mathrm{CZ}$ (42.8 g) during the common testing period 2009-2020. The difference in late-sown condition was also marginal. TGW in new late-sown varieties of CZ (MP 3336, HD 2932 and HD 2864) was $39.5 \mathrm{~g}$, whereas new material of PZ (HD 2932, HD 3090 and RAJ 4083) had TGW of $38.9 \mathrm{~g}$. It is a general perception that increasing the grain number (through tillers or spike length) is necessary to enhance the yield potential in wheat. This analysis has shown the promise as yield growth under normal planting had been derived from grain weight in NEPZ and PZ. It is a good sign for the breeder as it will prompt them to explore this route of productivity improvement in other environments as well.

The main reason of late planting of wheat is to accommodate remunerative crop rotations particularly rice-wheat belt of IGP. In certain areas of CZ, farmers prefer this practice as need of water for irrigation becomes comparatively less as the crop duration is reduced and economization of water is very important in this hot and dry region. Cotton based crop rotation also demands late sowing of wheat in CZ. Unlike IGP, time left for preparing field for wheat sowing after the preceding crop is not a problem in central-peninsular India. High productivity in the latesown wheat can keep this practice alive in central India but the relevance of late-sown wheat is debatable for the peninsular region. Productivity level of late-sown wheat in PZ is not as high as observed in CZ. More emphasis can be given to dicoccum or the rainfed durum in this region. Study also suggests that late planted wheat is not remunerative in NHZ. During 26 years of this analysis, just $2.8 \mathrm{t}$ /ha yield was obtained in a crop that took 146 days to mature. This kind of subsistence farming is under practice in very small area and the hill farmers adopt it only to produce wheat for domestic use.

\section{Acknowledgements}

The work is an outcome of a core project funded by ICAR (Project No. CRSCIIWBRCIL201500100182), New Delhi and the authors express their sincere thanks to the Director, ICAR-IIWBR for permitting the use of the data generated in the All India Coordinated Research Project (AICRP) on Wheat and Barley for this analysis. The efforts made by associated wheat research workers in trial conduct and data reporting are also acknowledged.

\section{Conflict of Interest}

Authors declare that they have no conflict of interest.

\section{Ethical Compliance Statement}

NA

\section{Author Contribution}

Conceptualization: DM; Initial Draft: DM, SKS, SK; Critical review and finalization: KV, GK and GPS.

\section{References}

1. Magrin GO, Hall AJ, Baldy C and Grondona MO. 1993. Spatial and interannual variations in the photothermal quotient: implications for the potential kernel number of wheat crops in Argentina. Agriculture and Forest Meteorology 67:29-41.

2. Mohan D, Nagarajan S, Singh RVP and Shoran J. 2001. Is the national wheat breeding programme demand driven? - An analysis. Current Science 81:749753.

3. Mohan D, Singh SS and Gupta RK. 2011. Vibrancy of the Indian wheats in upholding yield and quality under global environmental change. In: Wheat: 
Productivity Enhancement under Changing Climate. SS Singh, RR Hanchinal, Gyanendra Singh, RK Sharma, BS Tyagi, MS Saharan and Indu Sharma (eds), 87-94, Narosa Publishing House, New Delhi.

4. Mohan D, Tiwari V and Gupta RK. 2017. Progression in yield and value addition of Indian bread wheat. Indian Journal of Genetics and Plant Breeding 77(1):16-24.

5. Mohan D, G Krishnappa and GP Singh. 2020. Wheat improvement for growth and sustainability in yield under varying climatic conditions and diverse production environments of India. In. Improving Cereal Productivity through Climate Smart Practices (eds. Sareen S, Sharma P, Singh C, Jasrotia P, GP Singh and AK Sarial). Woodhead Publishing, Elsevier Inc. United Kingdom, pp. 269-288. https://doi.org/10.1016/B9780-12-821316-2.00016-9.

6. Ortiz R, Sayre KD, Govaerts B, Gupta R, Subbarao GV, Ban T, Hodson D, Dixon JM, Ortiz-Monasterio IJ, Reynolds M. 2008. Climate change: Can wheat beat the heat? Agric. Ecosyst. E Environ. 126:46-58.

7. Rajaram S and Braun H-J. 2008. Wheat yield potential. In: MP Reynolds, J Pietragalla and H-J Braun (eds.), International Symposium on Wheat Yield Potential: Challenges to International Wheat Breeding, 103-107, Mexico, D.F.: CIMMYT.

8. Rajaram S and Ginkel MV. 1996. Yield potential debate: Germplasm vs. Methodology, or both. In: Increasing Yield Potential in Wheat: Breaking the Barriers. MP Reynolds, S Rajaram and A. McNab (eds.), 11-17, Mexico, D.F.: CIMMYT.

9. Rajaram S. 2012. Research and development strategy to produce 100 million metric tons of wheat in India by 2030. In: Wheat: Productivity Enhancement under Changing Climate. SS Singh, RR Hanchinal, Gyanendra Singh, RK Sharma, BS Tyagi, MS Saharan, and Indu Sharma (eds.), 1-13, Narosa Publishing House, New Delhi.

10. Sharma I, Gyanendra Singh and Gupta RK. 2013. Wheat improvement in India. In: Proceedings of the Regional Consultation on Improving Wheat Productivity in Asia. Bangkok, Thailand; 26-27 April 2012, Raj
Paroda, S Dasgupta, Bhag Mal, SS Singh, ML Jat and Gyanendra Singh (eds.), 81-97.

11. Shoran J, Mohan D, Tyagi BS and Kumar J. 1998. Yield trials and nurseries: Information and benefits at what cost? In: Proceedings of the International Group Meeting on "Wheat Research Needs Beyond 2000 AD" held at Directorate of Wheat Research, Karnal, India during 12-14 August, 1997, S Nagarajan, Gyanendra Singh and BS Tyagi (eds.), 89-100, Narosa Publishing House, New Delhi.

12. Singh SS, Sharma RK, Gyanendra Singh, Tyagi BS and Saharan MS. 2011. 100 years of Wheat Research in India- $A$ saga of distinguished achievements. Directorate of Wheat Research - 132001, Haryana, pp. 281.

13. Slafer GA and Andrade HF. 1989. Genetic improvement in bread wheat (Triticum aestivum) yield in Argentina. Field Crops Research 21: 289-296.

14. Slafer GA, Calderini DF and Miralles DJ. 1996. Yield components and compensation in wheat: opportunities for further increasing yield potential. In: Increasing yield potential in wheat: breaking the barriers. MP Reynolds, S Rajaram, and A. McNab (eds.), 101133, Mexico, D.F.: CIMMYT.

15. Slafer GA, Satorre EH and Andrade FH. 1994. Increases in grain yield in bread wheat from breeding and associated physiological changes. In: Genetic improvement of field crops: Current status and development. GA Slafer (eds.), 1-68, Marcel Dekker, Inc.: New York.

16. Tandon JP and Sethi AP. 1986. Twenty five years of Coordinated Wheat Research 1961-86. Wheat Project Directorate, All India Coordinated Wheat Improvement Project, IARI, New Delhi 10012, India, pp. 287.

17. Zhonghu HE and Bonjean AP. 2013. Wheat production and technology improvement in China. In: Proceedings of the Regional Consultation on Improving Wheat Productivity in Asia Bangkok, Thailand; 26-27 April 2012, Raj Paroda, S Dasgupta, Bhag Mal, SS Singh, ML Jat and Gyanendra Singh (eds.), 73-80. 